\title{
Reinterpretation of Multiple Correspondence Analysis using the $K$-Means Clustering Analysis
}

\author{
Yong-Seok Choi ${ }^{1)}$, Gee Hong Hyun'2) and Kyung Hee Kim ${ }^{3)}$
}

\begin{abstract}
Multiple correspondence analysis graphically shows the correspondent relationship among categories in multi-way contingency tables. It is well known that the proportions of the principal inertias as part of the total inertia is low in multiple correspondence analysis. Moreover, although this problem can be overcome by using the Benzécri formula, it is not enough to show clear correspondent relationship among categories (Greenacre and Blasius, 1994, Chapter 10). In addition, they show that Andrews' plot is useful in providing the correspondent relationship among categories. However, this method also does not give some concise interpretation among categories when the number of categories is large. Therefore, in this study, we will easily interpret the multiple correspondence analysis by applying the $K$-means clustering analysis.
\end{abstract}

Keywords : Andrews' plot, $K$-means clustering, Multiple Correspondence Analysis

\section{1. 서론}

대응분석은 비정칙치분해(singular value decomposition)를 이용한 차원 축소와 함께 2 차원의 그 래프적 표현을 통해 분할표 자료의 행과 열 범주들간의 대응관계를 탐구하려는 것을 목적으로 한 다(Greenacre, 1994, pp. 3 8; 최용석, 2001, 1장).

대응분석이 다변량 자료분석으로 널리 알려진 때는 1980년대이다. 프랑스에서는 1960년대 Jean-Paul Benzécri에 의해 대응분석의 기하적인 면이 발전되어 졌으며, 일본에서는 1950년대 Chikio Hayashi에 의해 수량화 제 3 방법으로 개발되어 발전되었다. 대응분석의 기하적 - 수리적인 면은 Greenacre(1984, Chapter 4)와 Lebart et al. (1984, Chapter II)에서 자세히 소개하고 있다.

대응분석은 이원분할표에 적용되는 단순대응분석(simple correspondence analysis)과 다원분할표 에 적용되는 다중대응분석으로 나눌 수 있다. 단순대응분석은 대체로 처음 두 개의 주결여성에 대 응하는 제 1 축과 제 2 축에 의한 2 차원의 대응분석그림을 통하여 원자료의 행과 열의 대응관계를 충분히 보여줄 수 있지만, 다중대응분석은 비정칙값(singular value)의 제곱인 주결여성이 총결여

1) Associate Professor, Department of Statistics, Pusan National University, Pusan, 609-735, Korea

E-mail: yschoi@pusan.ac.kr

2) Department of Statistics, Pusan National University, Pusan, 609-735, Korea

E-mail: shoma00@yahoo.co.kr

3) Department of Statistics, Pusan National University, Pusan, 609-735, Korea 
성에서 차지하는 비율이 낮기 때문에 2 차원의 대응분석그림으로는 범주들 간의 대응관계를 정확 하게 파악할 수 없는 경우가 많다. 여기서 주결여성(principal inertia)이란 단순대응분석에서 대응 행렬과 다중대응분석에서는 버트행렬(Burt matrix)의 일반화비정칙값분해(generalized singular value decomposition)에서 비정칙값의 제곱에 해당한다. 이들 주결여성의 합을 총결여성이라 하며 처음 $s$ 개의 주결여성이 총결여성에서 차지하는 비율을 $s$ 차원 대응분석의 적합도내지는 설명력이 라 한다. 대개 처음 $s$ 개 주결여성이의 설명력이 $70 \%$ 이상이면 $s$ 차원의 대응분석이 법주들의 관계 를 잘 설명한다고 본다.

Greenacre와 Blasius(1994, Chapter 10)는 Benzécri 공식을 사용하여 주결여성의 차원도 줄이면 서 주결여성의 비율을 높인 수정된 주결여성과 이에 의해서 변환된 주좌표에 대한 수정된 다중대 응분석을 하고자 한다. 그러나 이 새로운 대응분석그립도 범주들의 대응관계를 명확히 보여주지 못한다. 이들은 추가적으로 앤드류스 그림을 통해 재해석하고 있다. 그러나 앤드류스 그림에서는 자료의 모든 정보를 시각적으로 표현할 수 있는 장점은 가지고 있지만 이 방법은 탐색적인 방법 으로 객관적이지 못하고 범주가 많은 경우 자료의 구조를 파악하기 힘든 문제점이 있다.

이런 문제점을 해결하기 하기 위해 군집분석을 생각할 수 있다. 이를 통하여 연관성 있는 범주 들을 묶어 대응시켜 보자는 것이다. 군집분석에는 계층적-비계층적 군집분석이 있다. 본 논문에 서는 그 중 비계층적 군집분석인 $K$-평균 군집분석을 활용하여 수정된 주결여성을 사용한 다중대 응분석을 재해석하고자 한다.

\section{2. 다중대응분석}

\section{1. 다중대응분석의 대수적 이론}

본 논문에서 사용하는 자료(이후 사회경제적 자료)는 Lebart et al. (1984, pp. 100 108)에서 재 인용 하였다. 이는 프랑스의 18 세 이상 남녀 1000 명을 대상으로 총 25 가지 분류변수 $(J=25$;

SEXM, SEXF, EDU1 EDU5, LOD1 LOD4, STO1, STO2, HOU1, HOU2, AGE1 AGE5, SIZ1 SIZ5)를 포함하는 7가지 범주 $Q=7$; 성별, 교육수준, 주거상태, 주식소유, 동산소유, 나이, 거주지 역규모)에 대한 사회경제적 설문조사를 통해 얻어진 자료이다. 이 설문자료를 활용하여 다중대응분 석을 하기 위해서는 각 범주와 분류변수에 따라 0 과 1 로만 나타내어 만든 표시행렬 $Z$ 의 내적곱인 버트행렬(burt matrix) $B=Z Z$ 를 구성해야 한다. 다음으로 대응분석그림의 좌표를 얻기 위해서, 버트행렬 $B$ 의 일반화비정칙값분해에 의해 표준 열좌표는 다음과 같이 표현할 수 있다.

$$
\Gamma=R \Gamma\left(D_{\lambda}\right)^{-1 / 2}=\left[\begin{array}{c}
\Gamma_{1} \\
-\Gamma_{2} \\
\hline \vdots \\
\hline \Gamma_{Q}
\end{array}\right]
$$

여기서 $D_{\lambda}$ 는 주결여성 $\lambda_{k}$ 의 대각행렬 $\left(\lambda_{1}>\lambda_{2}>\cdots>0, k=1,2, \ldots\right)$ 이고, $R$ 은 버트행렬 
$\boldsymbol{B}=Z Z$ 의 행프로파일 행렬이며 $\Gamma_{q}=(1 / Q)\left(\Gamma_{q}+\sum_{q \neq q^{\prime}} R_{q q^{\prime}} \Gamma_{q^{\prime}}\right)\left(D_{\lambda}\right)^{-1 / 2}(q=1, \ldots, Q)$ 이다. 그리고 $R_{q q^{\prime}}$ 는 버트행렬 $B$ 의 비대각상 행렬 $Z_{q}^{\prime} Z_{q}\left(q \neq q^{\prime}\right)$ 의 행 프로파일행렬이다.

사회경제적 자료에 대한 버트표의 다중대응분석 결과 <표 2.1>를 살펴보면 2차원 대응분석그림을 위한 설명력으로 주결여성이 각각 $9.72 \%$ 와 $8.49 \%$ 로 이들의 합이 $18.21 \%$ 으로 설명력이 낮아 2 차 원 다중대응분석그립만으로 원자료 범주들의 대응관계를 충분히 보여줄 수 없게 된다. 이런 문제 점을 극복하고자 Benzécri(1979)는 식 (2.2)의 Benzécri 공식을 사용하여 주결여성의 차원도 줄이 면서 주결여성의 비율을 높게 하는 수정된 주결여성으로 다중대응분석을 하고자 한다.

$$
\widetilde{\lambda}_{k}=\left[\frac{Q}{Q-1}\left(\lambda_{k}-\frac{1}{Q}\right)\right]^{2}
$$

이다. 여기서 $k$ 는 $\lambda_{k}>1 / Q$ 보다 큰 경우에 해당한다.

<표 2.1> 다중대웅분석에서의 주결여성

\begin{tabular}{c|c|c|c}
\hline 비정칙값 & 주결여성 & $\begin{array}{c}\text { 주결여성의 } \\
\text { 백분율(\%) }\end{array}$ & $\begin{array}{c}\text { 누적 } \\
\text { 백분율(\%) }\end{array}$ \\
\hline \hline 0.50002 & 0.25002 & 9.72 & 9.72 \\
0.46729 & 0.21836 & 8.49 & 18.21 \\
0.42972 & 0.18466 & 7.18 & 25.39 \\
0.41786 & 0.17461 & 6.79 & 32.18 \\
0.40129 & 0.16104 & 6.26 & 38.44 \\
0.39753 & 0.15803 & 6.15 & 44.59 \\
0.39265 & 0.15418 & 6.00 & 50.59 \\
0.38172 & 0.14571 & 5.67 & 56.26 \\
0.37535 & 0.14089 & 5.48 & 61.74 \\
0.36662 & 0.13441 & 5.23 & 66.97 \\
0.35915 & 0.12899 & 5.02 & 71.99 \\
0.35396 & 0.12529 & 4.87 & 76.86 \\
0.34977 & 0.12234 & 4.76 & 81.62 \\
0.34304 & 0.11767 & 4.58 & 86.20 \\
0.32555 & 0.10598 & 4.12 & 90.32 \\
0.30939 & 0.09572 & 3.72 & 94.04 \\
0.29484 & 0.08693 & 3.38 & 97.42 \\
0.25810 & 0.06661 & 2.59 & 100.00 \\
\hline
\end{tabular}

<표 2.2>에는 식 (2.2)의 공식에 의해서 <표 2.1>의 수정된 주결여성 $\widetilde{\lambda}_{k}$ 를 계산해 두었다. 이 표에 따르자면, 주결여성의 개수가 18 개에서 8 개로 줄어들고 2 차원까지의 설명력은 각각 $55.65 \%$ 와 $27.63 \%$ 이며 이들의 합이 $83.27 \%$ 로 <표 2.1 >의 주결여성 $18.21 \%$ 보다 높은 주결여성의 비율을 얻을 수 있다.

다음으로 식 (2.1)의 표준 열좌표 $\Gamma$ 를 생각해보자. $\Gamma$ 에서 수정된 주결여성 개수만큼의 주축까 지의 표준 열좌표를 $\Gamma^{*}$ 라 하면 수정된 주결여성을 이용한 주좌표(principal coordinates)는 
508 Yong-Seok Choi, Gee Hong Hyun and Kyung Hee Kim

$$
\widetilde{G}^{*}=\Gamma^{*} \widetilde{D_{\lambda}}
$$

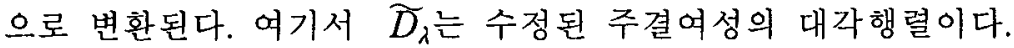

<표 2.2> Benzécri 공식을 활용한 수정된 주결여성

\begin{tabular}{c|c|c|c}
\hline 비정칙값 & 주결여성 & $\begin{array}{c}\text { 주결여성의 } \\
\text { 백분율 }(\%)\end{array}$ & $\begin{array}{c}\text { 누적 } \\
\text { 백분율 }(\%)\end{array}$ \\
\hline \hline 0.125023 & 0.015631 & 55.65 & 55.65 \\
0.088091 & 0.007760 & 27.63 & 83.27 \\
0.048767 & 0.002378 & 8.47 & 91.74 \\
0.037041 & 0.001372 & 4.88 & 96.62 \\
0.021209 & 0.000450 & 1.60 & 98.22 \\
0.017699 & 0.000313 & 1.12 & 99.34 \\
0.013205 & 0.000174 & 0.62 & 99.96 \\
0.003329 & 0.000011 & 0.04 & 100.00 \\
\hline
\end{tabular}

<표 2.3>은 자료의 범주에 따라 8 개의 수정된 주결여성에 의해 변환된 제 1 축에서 제 8 축까지 의 좌표 $\widetilde{G}^{*}$ 이다. 이는 새로운 다중대응분석그림을 위한 좌표이기도 하다.

<표 2.3> 주좌표 $\widetilde{G}^{*}$

\begin{tabular}{|c|c|c|c|c|c|c|c|c|}
\hline & 제1축 & 제2축 & 제3축 & 제4축 & 제5축 & 제6축 & 제7축 & 제8축 \\
\hline 1 SEXM & & & & & & & & \\
\hline 2 SEXF & 2215 & -0.001269 & -.0003420 & -.0001194 & 0.0001671 & 0.000101 & 0.0000163 & 5. $1554 E-6$ \\
\hline 3 EDU1 & -0.001956 & 0.001121 & 0.0003021 & 0.0001055 & -0.000148 & -0.000089 & -0.000014 & $-4.553 E-6$ \\
\hline 4 EDU2 & 0.004140 & -0.002649 & -.0024218 & 0.0005383 & 0.0003297 & 0.0000321 & -0.000022 & $-9.172 E-6$ \\
\hline 5 EOU3 & 0.006779 & -0.004653 & 0.0002776 & -.0006953 & -0.000131 & 0.000041 & -0.000021 & $1.7165 \mathrm{E}-6$ \\
\hline 6 EOU4 & -0.006214 & -0.000008 & 0.0007132 & 0.0008097 & -0.000131 & -0.000409 & -0.000036 & $5.2707 E-6$ \\
\hline 7 EOU5 & -0.008536 & 0.003539 & 0.0019111 & 0.0011810 & -0.000019 & 0.0001926 & 0.0000357 & $9.972 E-7$ \\
\hline $8 \quad L 001$ & -0.004056 & 0.009673 & -.0003291 & -.0013662 & 0.000017 & 0.0000902 & 0.0000728 & $1.5103 E-6$ \\
\hline Lot & -0.001728 & -0.005494 & 0.0037628 & -.0005040 & 0.0003776 & 0.0001917 & -0.000022 & $-1.185 E-6$ \\
\hline Lut & 0.018073 & 0.000523 & -.0001489 & 0.0001915 & -0.000084 & -0.000035 & 0.0000193 & $2.4175 E-6$ \\
\hline 10 L003 & -0.009064 & 0.000872 & -.0005926 & -.0002293 & -0.000049 & -0.000077 & -0.000035 & $-1.751 E-6$ \\
\hline $11\llcorner 004$ & -0.005246 & 0.000778 & -.0015773 & 0.0020485 & 0.0000835 & 0.0004503 & 0.0002543 & 5.8211E-6 \\
\hline 12 ST01 & 0.015328 & 0.013742 & 0.0011421 & -.0000293 & 0.0000627 & -0.000014 & -0.000073 & $2.6217 E-6$ \\
\hline 13 ST02 & -0.002110 & -0.001892 & -.0001572 & 0.0000040 & $-8.637 \mathrm{E}-6$ & $1.9021 \mathrm{E}-6$ & 0.00001 & $-3.609 E-7$ \\
\hline 14 HOU1 & 0.021515 & 0.012979 & 0.0022349 & 0.0007791 & -0.000066 & 0.00003 & -0.000107 & 1. 1764E-6 \\
\hline $15 \mathrm{H}$ & -0.001922 & -0.001159 & -.0001996 & -.0000696 & $5.8563 \mathrm{E}-6$ & $-2.681 E-6$ & $9.5854 \mathrm{E}-6$ & $-1.051 \mathrm{E}-7$ \\
\hline 16 AGE 1 & -0.011266 & 0.000115 & 0.0004979 & 0.0046390 & 0.0003721 & -0.000286 & 0.0000808 & $1.737 \mathrm{E}-6$ \\
\hline 17 AGE2 & -0.014425 & 0.002045 & -.0003736 & -.0000787 & -0.000153 & 0.0001177 & -0.000072 & $6.0031 E-6$ \\
\hline $\begin{array}{l}\text { 1) AGE2 } \\
18 \text { AGE3 }\end{array}$ & -0.001149 & -0.001581 & 0.0014887 & -.0005376 & 0.0001067 & -0.00006 & 0.0000992 & $-2.848 E-7$ \\
\hline & 0.010155 & -0.002658 & -.0003453 & 0.0002195 & -0.000452 & 0.000025 & -0.000089 & $-7.325 E-6$ \\
\hline $\begin{array}{l}19 \text { AGE4 } \\
20 \text { AGE5 }\end{array}$ & 0.014873 & 0.003272 & -.0023237 & -.0000948 & 0.0004148 & $-5.592 \mathrm{E}-6$ & -0.000024 & $-4.367 E-7$ \\
\hline (1) $\mathrm{sIz}$ & 0.019995 & -0.008077 & -.0005176 & 0.0006118 & -0.000679 & 0.0000676 & 0.000168 & 0.0000113 \\
\hline $21 \mathrm{SIZI}$ & 0.007629 & -0.002624 & 0.0027003 & 0.0004756 & 0.0001227 & 0.0002285 & $6.2555 \mathrm{E}-7$ & -0.000019 \\
\hline 22 sız2 & 0.004151 & -0.002256 & 0.0005504 & -.0002829 & 0.0003657 & -0.000385 & 0.0000158 & 4. $1925 \mathrm{E}-6$ \\
\hline $23 \mathrm{SIZ3}$ & -0.004057 & -0.001123 & -.0001580 & 0.0001592 & 0.0000617 & 0.0001274 & -0.000177 & $3.7135 \mathrm{E}-6$ \\
\hline 24 SIZ4 & & 0.005101 & -.0007248 & -.0002915 & -0.000118 & 4. $1016 \mathrm{E}-8$ & 0.0001273 & $-3.86 \mathrm{E}-6$ \\
\hline $25 \mathrm{~s}$ & & & & & & & & \\
\hline
\end{tabular}


일반적으로 처음 두 개의 주결여성에 대응하는 제 1 축과 제 2 축에 의한 2 차원의 대응분석그림 <그림 2.1>로 자료를 해석한다. 그러나 이 그림으로는 범주들 간의 대응관계를 전체적으로 명확 하게 보여주지 못할 뿐 아니라, AGE1과 LOD4는 <그림 2.2>의 제 1축과 제 4축에 의한 대응분 석그림에서 제 4 축에서 다른 범주들보다 두드러지게 높은 값을 가져 2 차원 보다는 더 높은 차원에 서 해석되어어야 할 범주이다. 이런 범주들의 대응관계를 자세히 알아보기 위해 Greenacre와 Blasius(1994, Chapter 10)는 앤드류스 그림을 이용하고 있다. 이는 2.2절에서 자세히 보이고자 한 다.

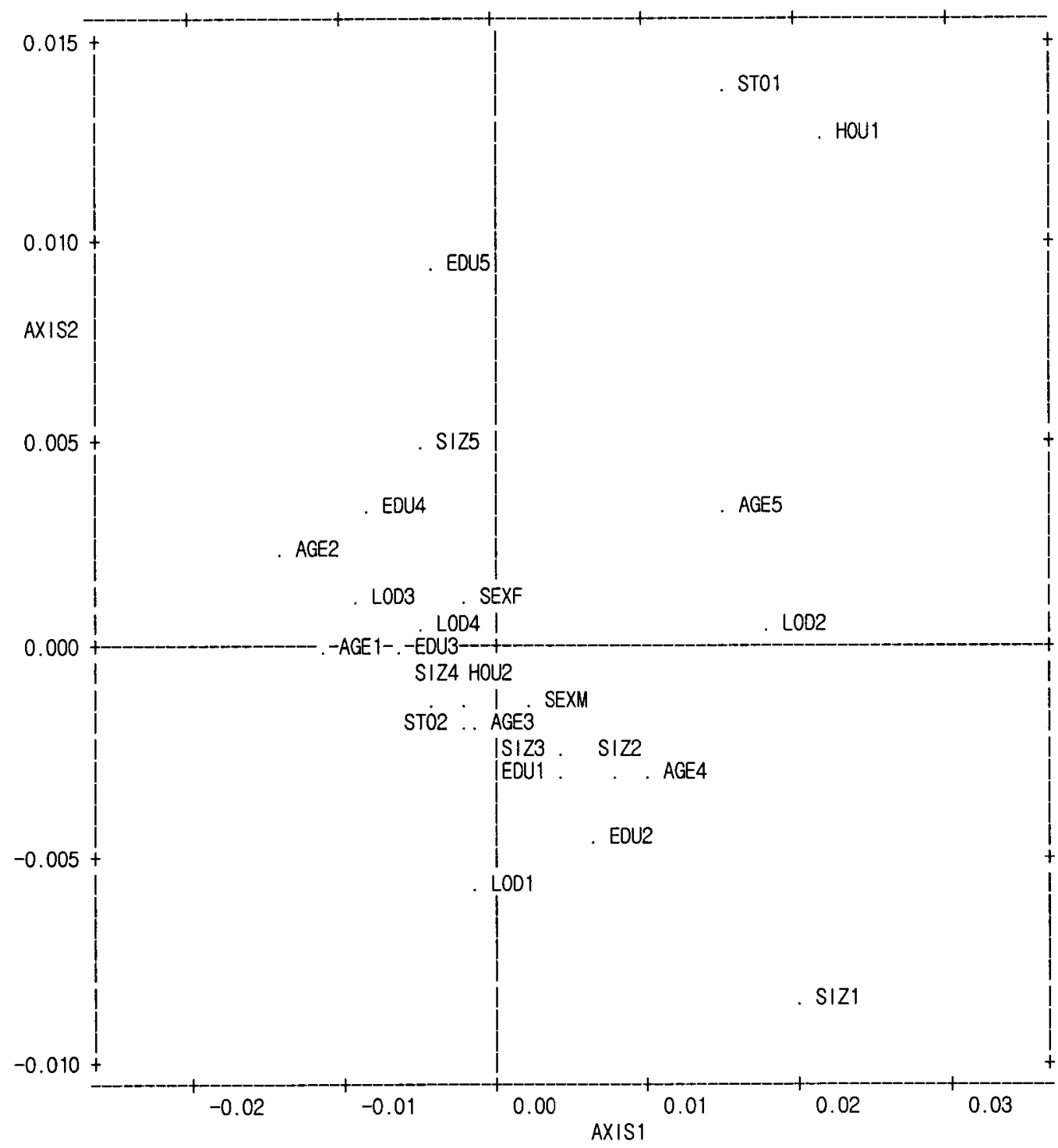

<그림 2.1> 제 1축(AXIS1)과 제 2축(AXIS2)에 의한 대응분석그림 
510 Yong-Seok Choi, Gee Hong Hyun and Kyung Hee Kim

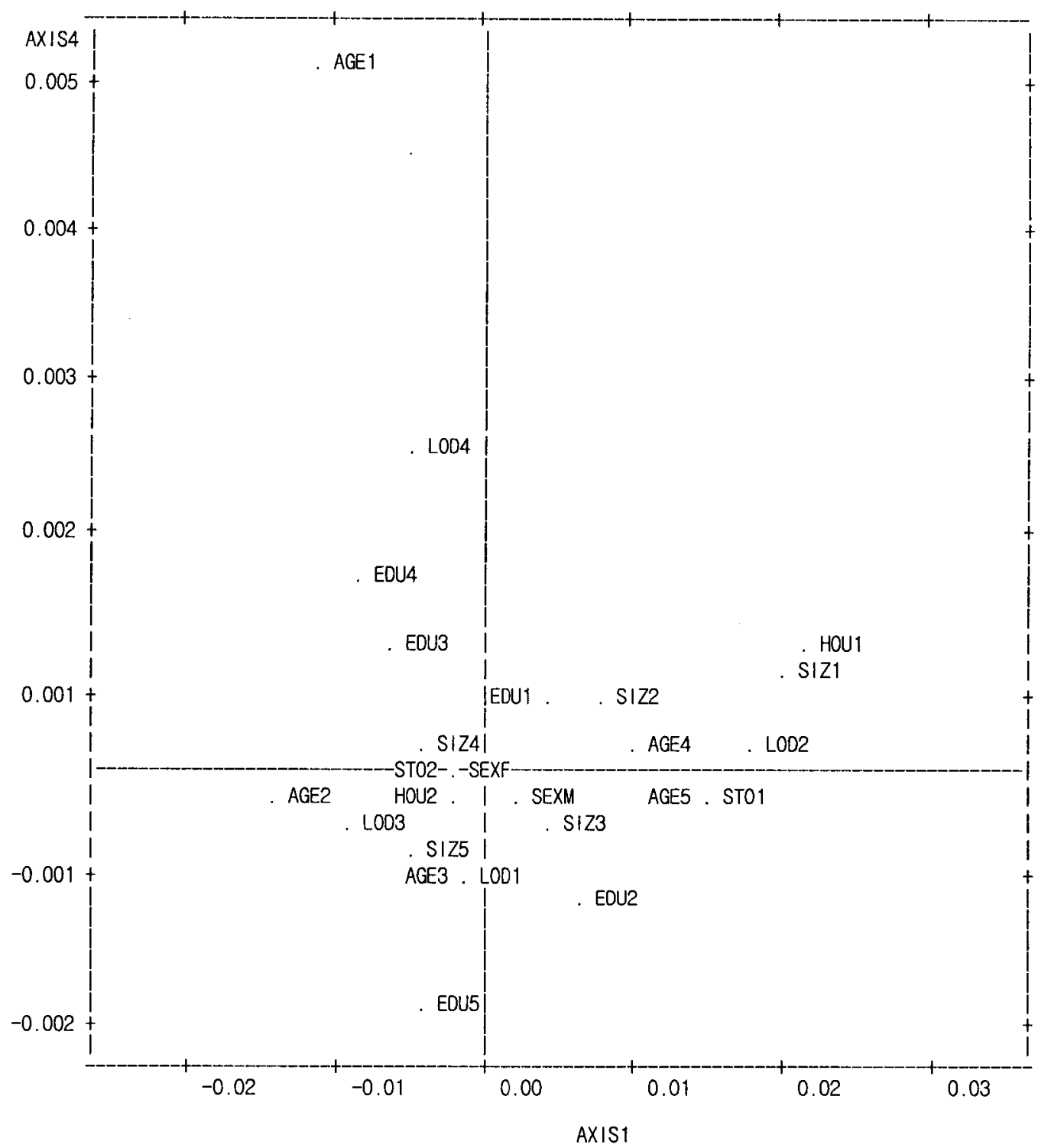

<그림 2.2> 제 1축(AXIS1)과 세 4축(AXIS4)에 의한 대응분석그림

\section{2. 앤드류스 그립을 이용한 다중대응분석의 재해석}

Andrews(1972)는 다변량 자료의 좌표점을 나타내기 위해 다음과 같은 함수를 제안하였다.

$$
\begin{aligned}
f_{X}(t) & =X_{1} / \sqrt{2}+X_{2} \sin t+X_{3} \cos t+X_{4} \sin 2 t+X_{5} \cos 2 t+\cdots \\
& =\boldsymbol{a}^{\prime}(t) X
\end{aligned}
$$

여기서 $-\pi<t<\pi, X=\left(X_{1}, X_{2}, \ldots, X_{k}\right)^{\prime}$ 는 $k$ 개의 변수로 이루어지는 관찰벡터이다. 
식 (2.4)에서 관찰벡터 $X_{1}, \ldots, X_{n}$ 에 대응하는 $n$ 개의 앤드류 곡선 $f_{X_{1}}(t), \ldots, f_{X_{*}}(t)$ 는 동일한 그림에 그려지고 앤드류스 곡선끼리 서로 비교하여 곡선의 모양이 유사한 경우에는 관 찰벡터가 서로 유사한 것이기 때문에 그 벡터끼리 군집화(clustering)할 수 있다.

<표 2.3>의 $\widetilde{G}^{*}$ 를 식 (2.4)의 관찰벡터 $X=\left(X_{1}, X_{2}, \ldots, X_{8}\right)^{\prime}$ 로 생각하면 <그림 $2.3>$ 의 앤 드류스 그림을 그릴 수 있다(SAS Institute Inc., 1999, pp. 33 -38). <그림 2.3>에서는 크게 (1) STO1, HOU1 (2) AGE2, LOD3 (3) AGE1, LOD4 (4) SEXM, SEXF, STO2, HOU2 (5) EDU5, SIZ5인 5개의 군집으로 묶어 줄 수 있다. AGE1, LOD4와 같은 범주는 <그림 2.1>에서는 해석하기 모호했던 범주로 제 4축에 의해 해석되어 질 수 있었으나 앤드류스 그림을 통해 두 범주가 하나의

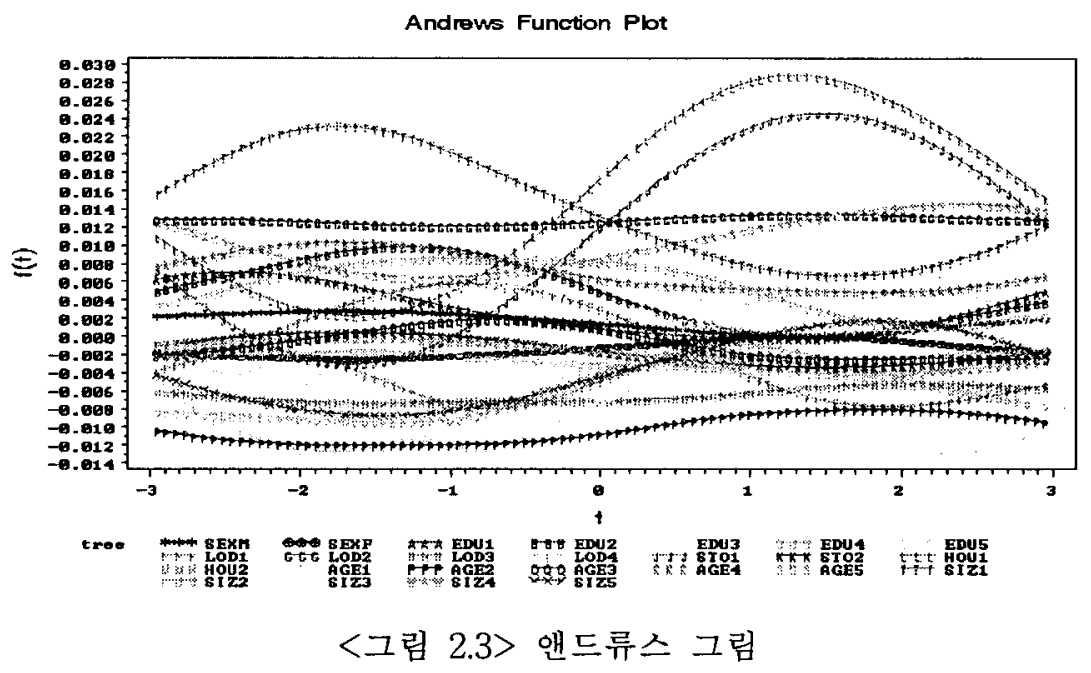

군집으로 묶여지고 있다. 그러나 이 방법은 탐색적인 방법으로 앤드류스 곡선의 유사함을 평가하는데 있어서 객관적이지 못하고 범주의 수가 많아지는 경우 $(n \geq 10)$ 각각의 곡선의 모양을 추적하거나 비교하기가 어려워져 자료의 구조를 파악하기 힘든 문제점이 있다.

\section{3. 군집분석을 활용한 다중대응분석의 재해석}

다중대옹분석의 해석에 있어서 군집분석을 활용할 수 있다. 군집분석 방법 중 계산이 비교적 간 단하고 특히 큰 자료의 개체 군집화에 효율적인 $K$-평균 군집분석을 활용하여 다중대응분석을 재 해석하고자 한다.

이 때 군집의 수 $K$ 와 초기 시드점은 임의로 선택되어질 수 있지만 Sharama(1996, pp. 221 232)는 계층적 방법에서 나온 군집의 수를 $K$ 개 초기 군집의 수로 두고 초기 시드점으로는 계층 적 방법에서의 군집 중심을 사용하고 있다. 특히, 군집화를 위한 유사성의 척도로 표준화된 유클 리드거리를 사용하였다. 본 논문에서도 이 방법을 따르기로 한다.

군집의 수 $K$ 를 결정하는 방법으로는 평균제곱 표준편차근(root-mean-square standard deviation; RMSSTD), 반부분(semipartial) $R^{2}, R^{2}$, 군집간의 거리 등이 있는데, 4 가지 모두 대동소이한 결 
과를 보여주었다. 따라서 본 논문에서는 군집의 개수에 대응되는 RMSSTD와 $R^{2}$ 의 값을 이용하 여 군집의 개수를 정하고자 한다. 군집분석의 목적은 군집 내에서는 동질적이어야 하므로 군집의 개수에 대응되는 RMSSTD의 값을 그려서 급격한 감소가 발생하는 곳에서 대응되는 군집의 수를 정할 수 있고, $R^{2}$ 값은 클수록 군집간에는 서로 다르므로 군집의 수에 대응되는 $R^{2}$ 의 값을 그려 서 급격한 증가가 발생하는 곳에서 대응되는 군집의 개수를 정할 수 있다. <그림 3.1>과 <그림 $3.2>$ 는 <표 2.3>에 대한 계층적 방법에서 나온 RMSSTD와 $R^{2}$ 의 값을 그린 것이다 $\bigcirc$ : 단일연 결법, * : 완전연결법, $\square:$ Ward의 방법, $\triangle:$ 중심연결법). (그림 $3.1>$ 에서 단일연결법은 군집의 수 가 4개 또는 8개일 때 RMSSTD의 값이 급격히 감소하고 있고, 완전연결법과 Ward의 방법에서는 군집의 수가 4 개 또는 7 개일 때 RMSSTD의 값이 급격히 감소하고 있다.

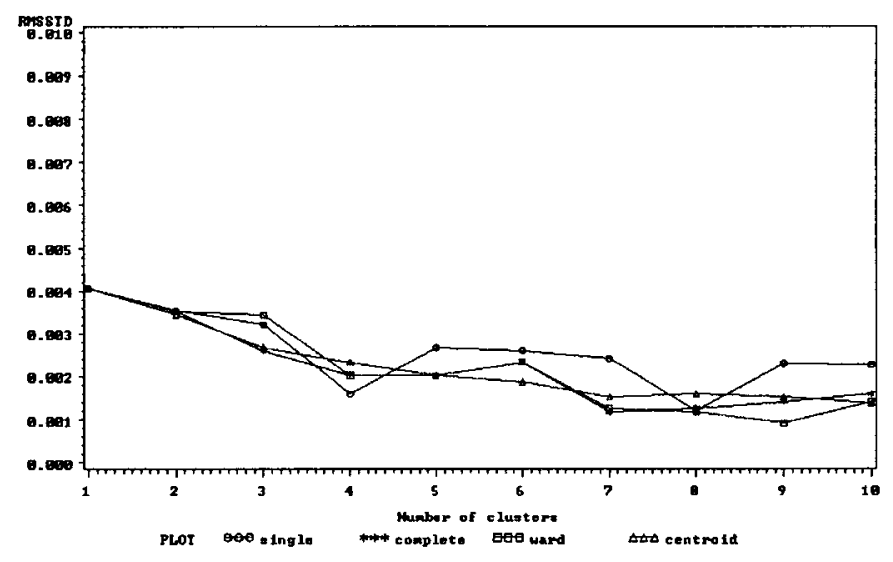

<그립 3.1> RMSSTD의 그림

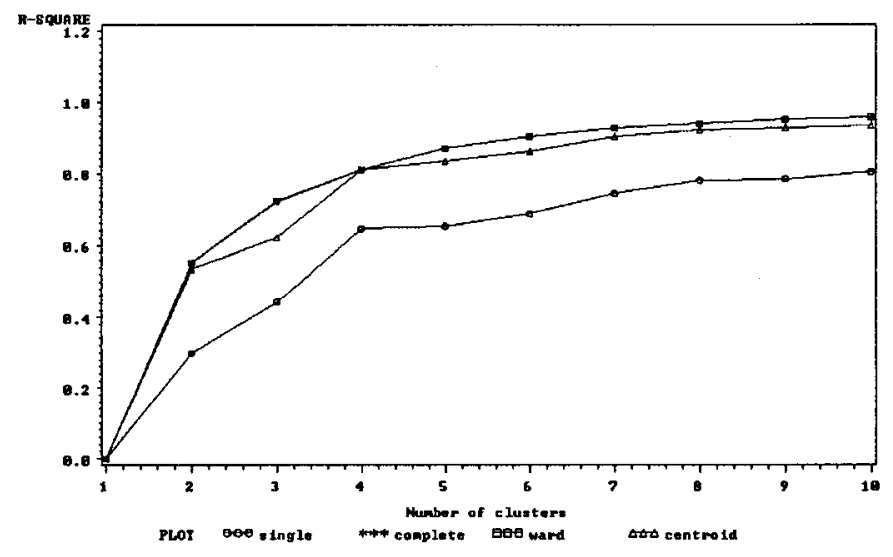

<그림 3.2> $R^{2}$ 의 그림 
<그림 3.2>에서는 4 가지 방법 모두 군집의 개수가 2 개 또는 4 개일 때 $R^{2}$ 의 값이 급격히 증가 하고 있다. 따라서 두 그립을 통한 군집의 수는 4 개로 결정할 수 있다.

초기 시드점으로는 단일연결법, 완전연결법, Ward의 방법, 중심연결법 등의 계층적방법에서의 군집중심을 사용한다. 이들 방법 중 어느 것을 사용해도 본 연구에서는 범주들의 최종 $K$-평균 군 집화 결과는 동일하므로 그 결과 중 중심연결법에서의 군집중심을 초기 시드점으로 사용하고 $K=4$ 인 $K$-평균 군집분석 결과를 정리한 것이 <표 3.1>이다. <표 3.1>을 살펴보면, 군집번호 1 에서는 교육수 준이 높을수록(EDU3 EDU5) 나이가 젊고(AGE1 AGE3) 거주지역 규모도 크다(SIZA SIZ5). 하지만 주식과 동산은 소유하지 않고 있음을 알 수 있다(STO1, HOU1).

앞서 살펴본 2.2절의 앤드류스 그림을 통한 군집화 결과와 <표 3.1>의 결과를 비교해 보면, AGE1, $\mathrm{AGE}$, LOD3, LOD4, EDU5, SIZ5는 앤드류스 그림의 결과에서 서로 다른 군집을 보였지만 <표 3.1> 에서는 같은 군집으로 묶여지고 있고, SEXF와 SEXM는 앤드류스 그림의 결과에서 같은 군집에 속해 있던 것으로 <표 3.1>에서는 서로 다른 군집에 속해 있음을 알 수 있다.

<표 3.1> 중심연결법 군집중심을 이용한 $K$-평균 군집분석

\begin{tabular}{c||l}
\hline 군집번호 & \multicolumn{1}{c}{ 대 응 범 주 } \\
\hline \hline 1 & SEXF, EDU3, EDU4, EDU5, LOD1, LOD3, LOD4 \\
& STO2, HOU2, AGE1, AGE2, AGE3, SIZ4, SIZ5 \\
\hline 2 & SEXM, EDU1, EDU2, AGE4, SIZ2, SIZ3 \\
\hline 3 & LOD2, AGE5, SIZ1 \\
\hline 4 & STO1, HOU1 \\
\hline
\end{tabular}

\section{4. 결론}

다중대응분석은 다원분할표 자료의 범주들 간의 대응관계를 살펴보기 위한 방법으로 버트행렬을 이용하여 분석하게 된다. 이때 주결여성이 총결여성에서 차지하는 비율이 낮기 때문에 설명력이 낮 은 2 차원 대응분석그림으로 범주들 간의 대응관계를 해석하기 힘든 경우가 있다. 이런 문제점을 해 결하기 위해 Benzécri 공식을 활용하여 낮은 주결여성을 높이는 수정된 다중대응분석을 소개하고 범주들의 대응관계를 알아보기 위해 앤드류스 그림을 이용한 Greenacre와 Blasius(1994, Chapter 10)의 방법을 소개하였다. 하지만 앤드류스 그림을 통해서도 자료의 구조를 파악하기란 힘들다. 왜 냐하면 범주의 수가 많은 경우 앤드류스 곡선의 모양을 비교하기 힘들 뿐만 아니라 객관적이지 못 하기 때문이다.

본 논문에서는 $K$-평균 군집분석을 활용하여 범주들 간의 대응관계를 해석하고자 하였다. 계층 적 방법에서 결정되어진 군집의 수 $K$ 개와 계층적 방법에서의 군집중심을 초기 시드점으로 사용 한 $K$-평균 군집분석 결과를 통해 2 차원 다중대응분석그림에서 해석되지 못했던 범주들 간의 대 응관계를 잘 파악할 수 있었고, 앤드류스 그림을 이용하여 자료의 구조를 파악할 때 생길 수 있는 문제점도 해결하였다. 
514 Yong-Seok Choi, Gee Hong Hyun and Kyung Hee Kim

\section{참고문헌}

[1] 김미경(2000). 저차원 $K$-평균 군집화, 「박사학위논문」, 고려대학교 중앙도서관, 서울.

[2] 최용석(2001). 「SAS 대응분석의 이해와 응용」, 자유아카데미, 서울.

[3] 허명회(1999). 「다변량 수량화」, 자유아카데미, 서울.

[4] Andrews, D. F. (1972). Plots of high-dimensional data, Biometrics, 28, 125-136.

[5] Benzécri, J. -P. (1979). Sur le calcul des taux d'inertie dans l'analyse d'un questionnaire. Addendum et erratum a [BIN.MULT]. Cahiers de L'analyse des Données, 4. 377-378.

[6] Greenacre, M. J. (1984). Theory and Application of Correspondence Analysis, Academic Press, London.

[7] Greenacre, M. and Blasius, J. (1994). Correspondence Analysis in the Social Sciences, Academic Press, London.

[8] Lebart, L., Morineau, A. and Warwick, K. (1984). Multivariate Descriptive Statistical Analysis: Correspondence Analysis and Related Techniques for Large Matrices, Wiley, New York.

[9] SAS Institute Inc. (1999). Applied Multivariate Statistics with SAS Software, Second Edition, SAS Institute Inc., NC.

[10] Sharama, S. (1996). Applied Multivariate Techniques, Wiley, New York. 